
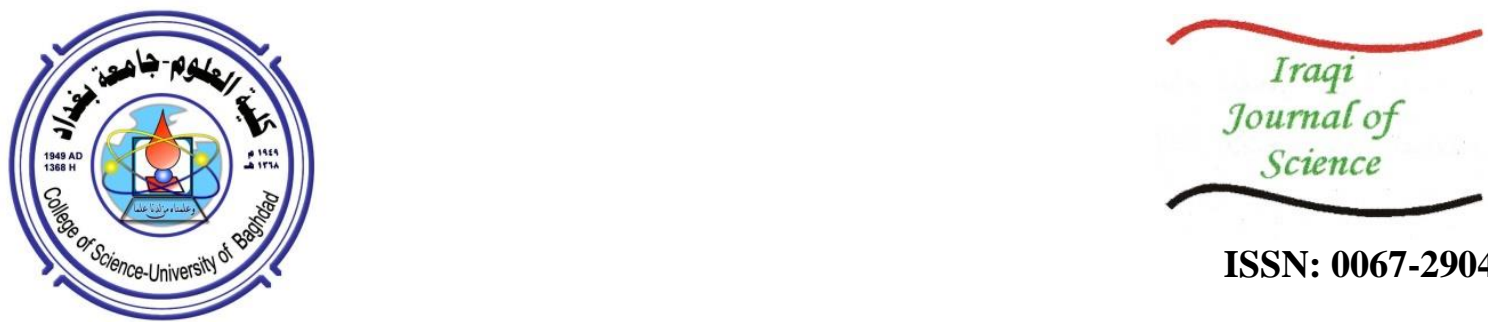

ISSN: 0067-2904

\title{
Random Noise Attenuation by using FDNAT Filter on Seismic Data in East Diwaniya, South Eastern - Iraq
}

\author{
Kamal K. Ali ${ }^{* 1}$, Reem K. Ibrahim ${ }^{1}$, Hassan A. Thabit ${ }^{2}$ \\ ${ }^{1}$ Department of Geology, College of Science, University of Baghdad, Baghdad, Iraq \\ ${ }^{2}$ Department of Seismic Data Processing, Oil Exploration Company, Ministry of Oil, Baghdad, Iraq
}

\begin{abstract}
The frequency dependent noise attenuation (FDNAT) filter was applied on 2D seismic data line DE21 in east Diwaniya, south eastern Iraq to improve the signal to noise ratio. After applied FDNAT on the seismic data, it gives good results and caused to remove a lot of random noise. This processing is helpful in enhancement the picking of the signal of the reflectors and therefore the interpretation of data will be easy later. The quality control by using spectrum analysis is used as a quality factor in proving the effects of FDNAT filter to remove the random noise.
\end{abstract}

Keywords: random noise attenuation, FDNAT filter

توهين الضوضاء العشوائيه باستخدام مرشح (FDANT) على البيانات الزلزاليه ثنائيه الابعاد في شرق

$$
\text { الايوانيه، جنوب شرق العراق }
$$

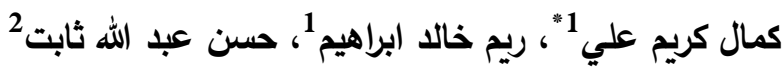

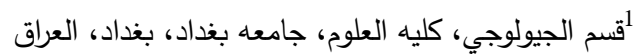

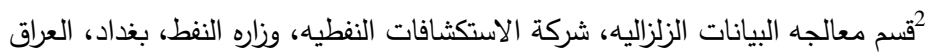

الخلاصة

مرشح توهين الضوضاء المعتمد على التردد يطبق على البيانات الزلزاليه ثنائيه الابعاد لخط دي 21 في

شرق الديوانيه جنوب شرق العراق. لتحسين نسبه الاشارة الى الضوضاء هذه البيانات الزلزاليه بعد تطبيق

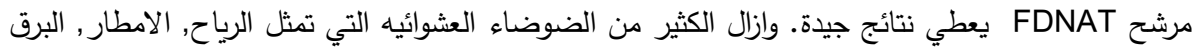

و صوت الرعد, تغيرات الضغط الجوي, تغيرات الحراره, الهزات الارضيه, المركبات ( السيارات, الثاحنات

الخ....), الطائرات, الناس, الحيوانات. ويساعد في تحسين التقاط الاشاره في العواكس وبالتالي تفسير البيانات

يصبح اسهل لاحقا. ضبط الجوده بواسطه استخدام تحليل الطيف اثبت تاثير ال FDNAT في ازاله الضوضاء

$$
\text { العشوائيه. }
$$

\section{Introduction}

Noises in seismic data have many different types. Thus, noise suppression is critical to seismic data processing and interpretation[1].One type of noise that exists in seismic data is Random noise [2] the other is coherent. Random noise should be attenuated before seismic interpretation, in order to improve the signal-to-noise ratio of seismic data[3].

When random noise is attenuated, the quality of seismic images is improved; hence, seismic events interpretation is greatly facilitated. The general interpretability of seismic data is increased by random noise filtering and also the performance of automatic horizon picking is improves [4].

* Email: kamalali@scbaghdad.edu.iq 
Many methods of random noise attenuation in seismic data have been developed to introduce over the years for processing. For high noise levels, $\mathrm{f}-\mathrm{x}$ deconvolution technique based on signal predictability [5] is an effective method[6].

Singular value decomposition (SVD) methods [7]decompose the signal and noise into different subspaces and can be used globally or locally [8] to suppress random seismic noise. Wavelet [9] and curvelet transforms [10] were also successfully employed for random noise attenuation.

Frequency-Dependent Noise Attenuation (FDNAT) is a method to process seismic data with multilevel processing (multi step flow). FDNAT is indicated for identifying such as: spike noise, noise and noised trace. FDNAT is a filter applied to the data in the frequency domain, range, both in CMP/CDP, offset or gather shot[11].

Seismic data are transformed to the time-frequency domain by Geovation. Then, the average amplitude index based on the decibel criterion is calculating to obtain the threshold and the time and frequency characteristics between the abnormal energy amplitudes and effective signals in a given time window. Finally, suppressed the outliers in the different frequency bands based on the calculated threshold[12]. The aim of this research is to enhance the signal to noise ratio by applying FDNAT filter on seismic data of study area.

\section{Study Area and Data Available}

The study area represents the eastern region of the city of Diwaniya, is located in the south east of Iraq within the province of Qadisiyah along the Euphrates River between the cities of Kut in the north and Samawa to the south (Figure-1) and can be determined coordinates in (U. T. M.) system.(Table-1).

Table 1-Cordinates of the study area, after Oil Exploration Company [13].

\begin{tabular}{|c|c|c|}
\hline Point & Easting & Northing \\
\hline A & 556000 & 3498000 \\
\hline B & 588000 & 3532000 \\
\hline C & 540000 & 3568000 \\
\hline D & 492000 & 3524000 \\
\hline E & 508000 & 3502000 \\
\hline F & 526000 & 3516000 \\
\hline
\end{tabular}

The area includes agricultural lands with abundant dense sand dunes. There are always flooded areas such as (victory evaporator ) located in the south- eastern part of the region, for the most lines to enter Hor Aldlameg the area in general flat and rising at sea level ranges from (7-20) meters [13].

Data Available for the current study include the seismic line of 2D seismic surveys of eastern Diwaniya (DE21). This line is part of 2D seismic survey achieved in 1991 by (O.E.C.). In the current study, these lines will be reprocessed with modern methods on the Geovation system.

The length of the seismic line is $85.26 \mathrm{~km}$ towards NW-SE while its field parameters are: source type is dynamite, No. of Channel are 96 , coverage is $2400 \%$, the sampling rate is $2 \mathrm{~ms}$, recording length is $5 \mathrm{sec}$, trace spacing is $70 \mathrm{~m}$ and the offset is $280 \mathrm{~m}$. 


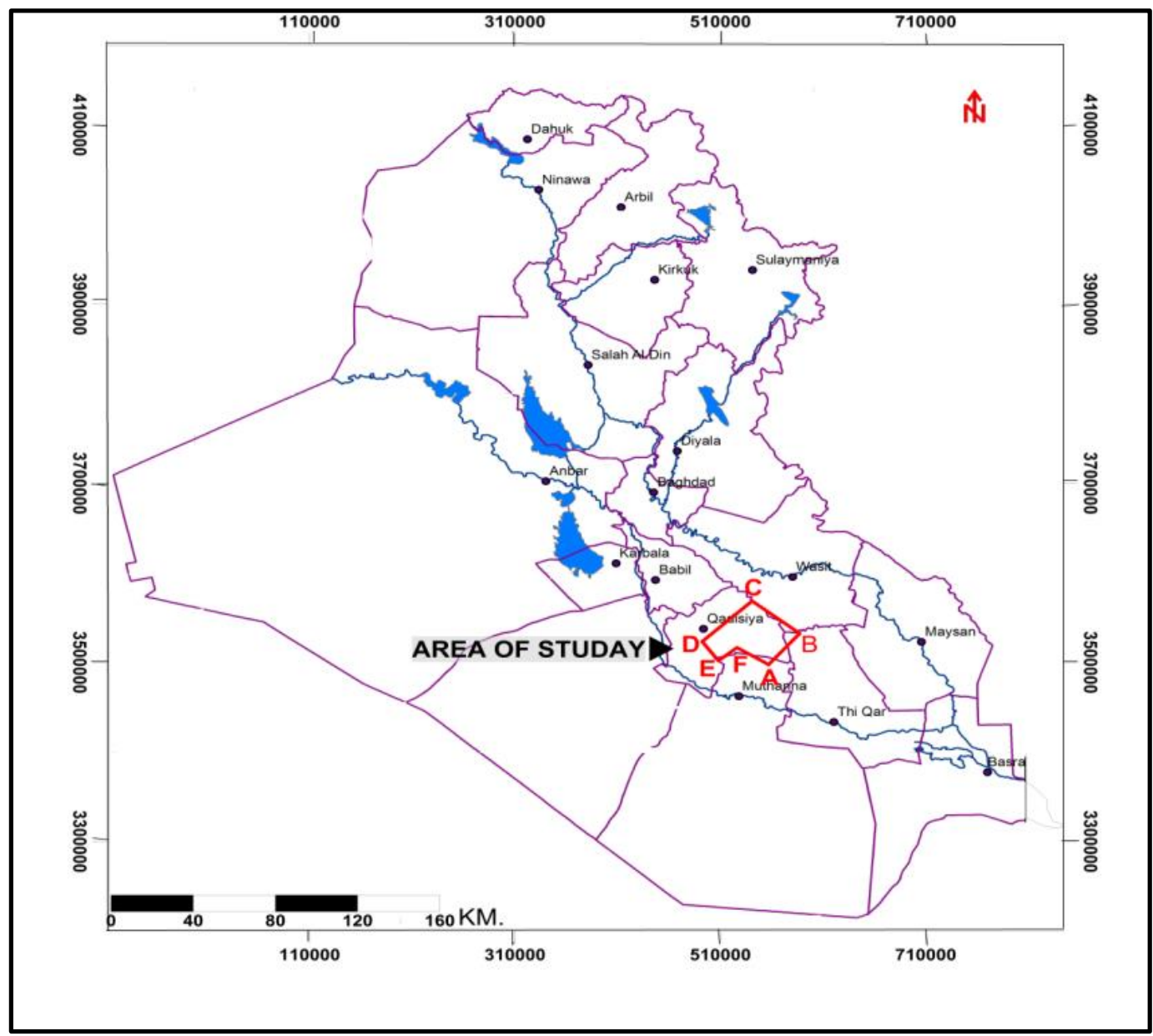

Figure 1- the geographical location of the study are [14].

\section{Frequency-Dependent Noise Attenuation (FDNAT)}

Spikes and ambient noise would be removed from the gathers using a special module (FDNAT) by Geovation system which attenuates high amplitude noise in decomposed frequency bands. It uses time variant threshold values of sample amplitudes and frequency -dependent, within defined trace neighborhoods to detect and suppress noise specific to different frequency ranges and different time [15].

FDNAT quantifies the sample strength and the strength of its neighborhood. The program then decides whether the sample is mostly noise by checking if its strength is threshold times its neighborhood strength. If noise is detected, the sampled amplitude will be scaled down to the lower level [16].

There are three criteria for calculating thresholds [12; 17-19]

1. The average amplitude criterion (AMC)

$$
T H D=\frac{1}{N} \sum_{i=0}^{N-1} f a b s(x(i))
$$

2. The root-mean-square amplitude criterion (RMSAC)

$$
T H D=\operatorname{sqrt}\left(\frac{1}{N} \sum_{i=0}^{N-1}[x(i)]^{2}\right)
$$

3. The average envelope amplitude criterion (AEAC)

$$
T H D=\frac{1}{N} \sum_{i=0}^{N-1} \operatorname{sqrt}\left([x(i)]^{2}+[\operatorname{hilbert}(x(i))]^{2}\right)
$$

Where THD is the threshold, $\mathrm{N}$ is the number of sampling points in the time window, $\mathrm{X}(\mathrm{i})$ is the amplitude of the i-th sampling point, fabs is an operator that takes absolute values, sqrt is the operator to calculate the RMS value, and hilbert denotes the Hilbert transform. 


\section{Data processing and Results}

FDNAT is proposed for seismic random noise attenuation to improve the signal to noise ratio $(\mathrm{S} / \mathrm{N})$ and then the quality of the seismic images.

The seismic data at first are transformed to the time frequency domain by Geovation system. The range of frequencies is separated to several windows each window is limited between two frequencies and compares with time and threshold. Then, the threshold is obtained by calculating the average amplitude index. The final parameters of FDNAT which subjected to test in the current seismic lines are shown in Table-2 also these values represent the final tested values which are applied to the data. The higher the threshold used, the less data is removed, and vice versa.

Table 2- the parameters of FDNAT

\begin{tabular}{|c|c|c|}
\hline Frequency & Time $(\mathrm{m} \mathrm{sec})$ & Threshold \\
\hline \multirow{3}{*}{$5,10,40,60 \mathrm{~Hz}}$. & 0 & 4 \\
\cline { 2 - 3 } & 1000 & 3 \\
\cline { 2 - 3 } & 3000 & 2 \\
\cline { 2 - 3 } & 5000 & 1 \\
\hline
\end{tabular}

The seismic data in both shots gather and the stack of the seismic lines DE21 is shown in figures (2A, 3A) contain random noise as pointed in (red color), so for denoising random noise the FDNAT is applied. This process gives good result after many times the testing of threshold in the windows of time and frequency. For example, when tested values of threshold are 8 in frequency window of 5-10 $\mathrm{Hz}$ and time window of $0-1000 \mathrm{msec}$, these values give bad denoising while when values in the table (2) are used it gives good results of denoising as shown in Figures-(2B, 3B). The Figure-(2C) in shot gather represents the noise which is removed from the input data and this is certifying usefulness of the FDNAT processing.

Spectrum analysis is used as QC for the FDNAT processing for attenuating random noise. This analysis depends on the relationship between frequency and amplitude. The spectrum analysis for the of the seismic line DE21 (Figure-4) shows that random noise has high amplitude within the lowfrequency range (0-15) Hz. (green line) while the signal (red line) has low amplitude within the same range, when FDNAT is applied on DE21 (Figure-5), it is highly obvious that signal to noise ratio is increased within the range of frequency $(0-30) \mathrm{Hz}$ and the signal is enhanced, that means this step of processing is good.

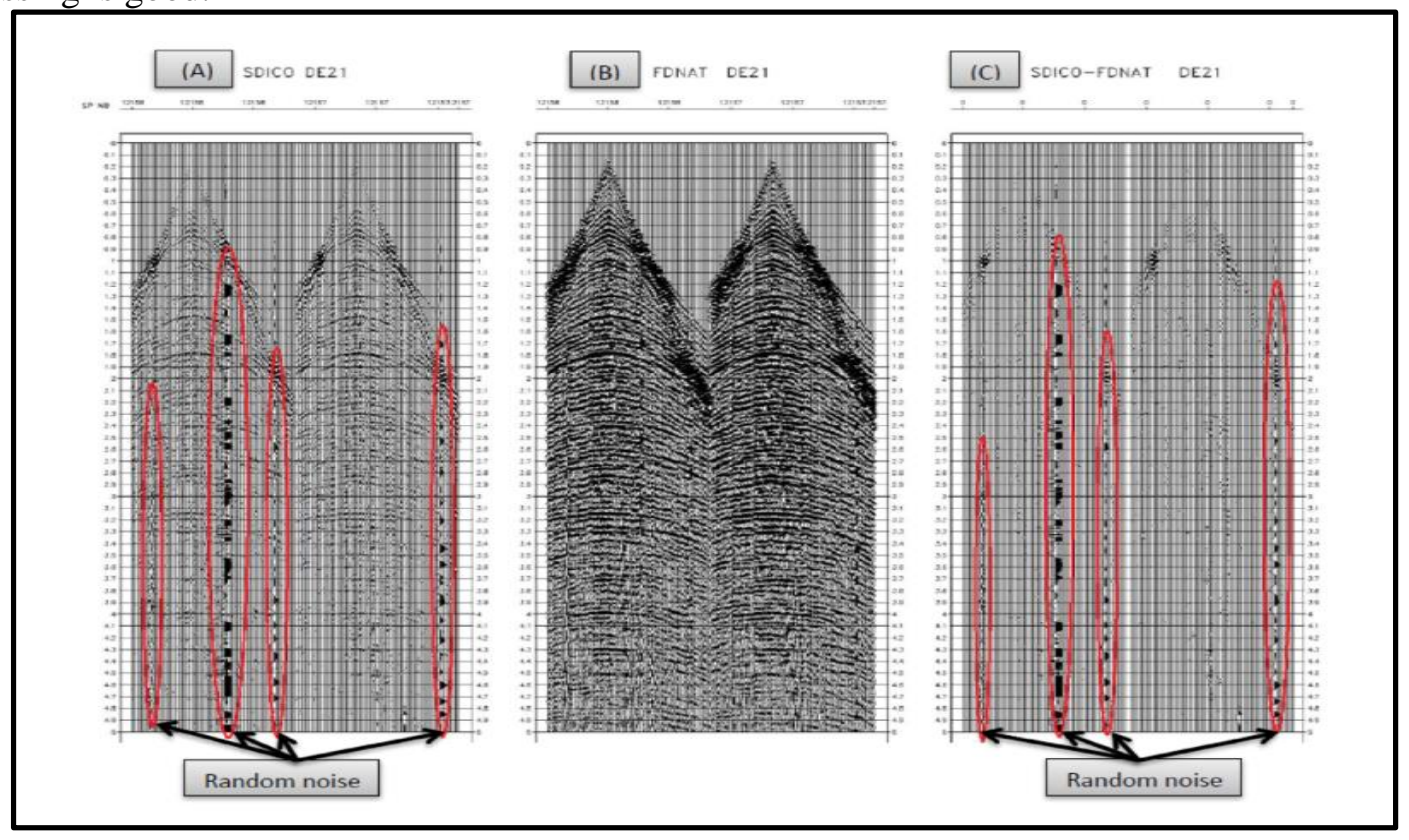

Figure 2- (A) Input Shots before FDNAT (B) Output Shots after FDNAT (C) Difference for FDNAT applied for the seismic line DE21. 


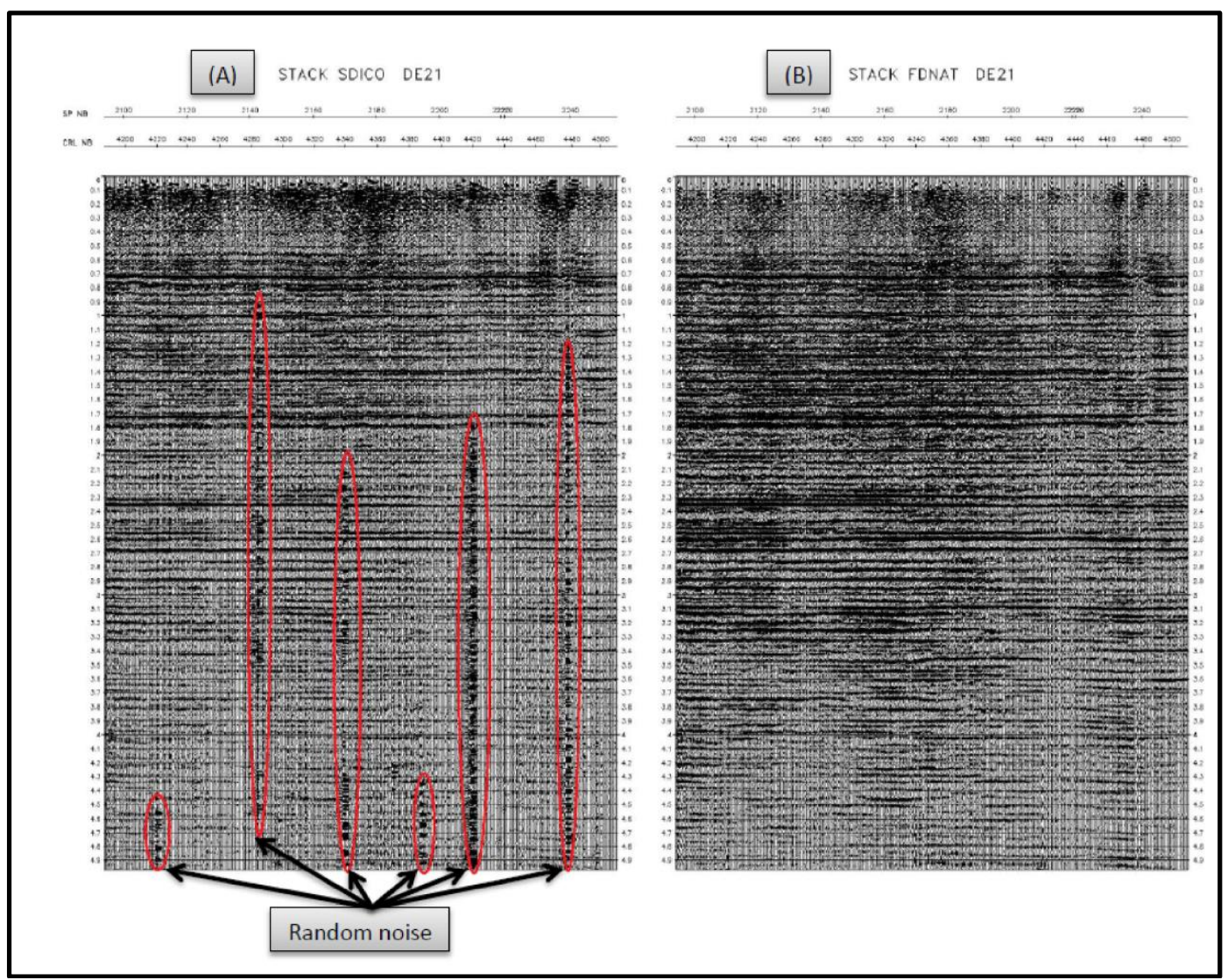

Figure 3- (A) Input stack before FDNAT (B) Output stack after FDNAT for the seismic line DE21

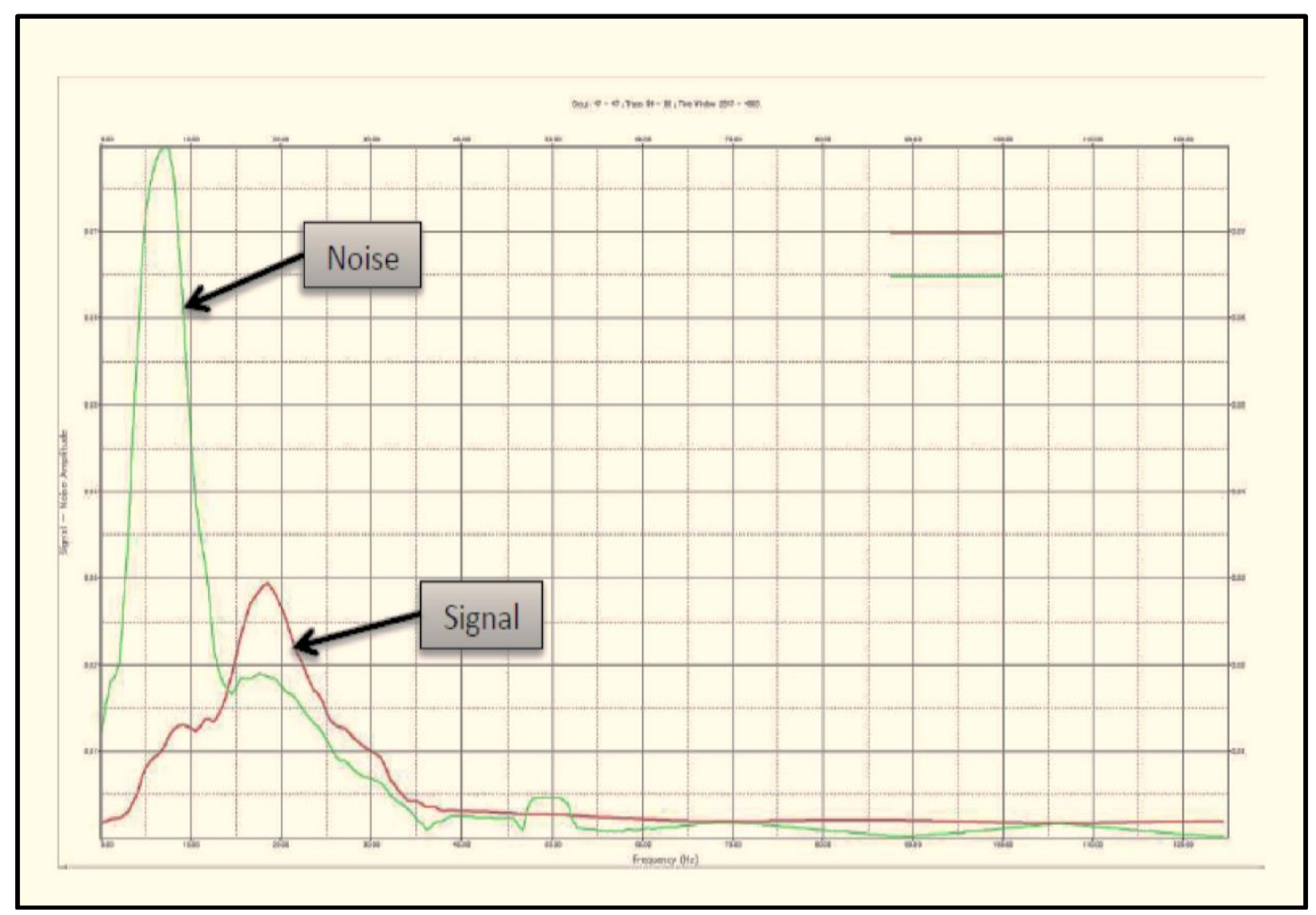

Figure 4- Spectrum analysis for the seismic line DE21. 


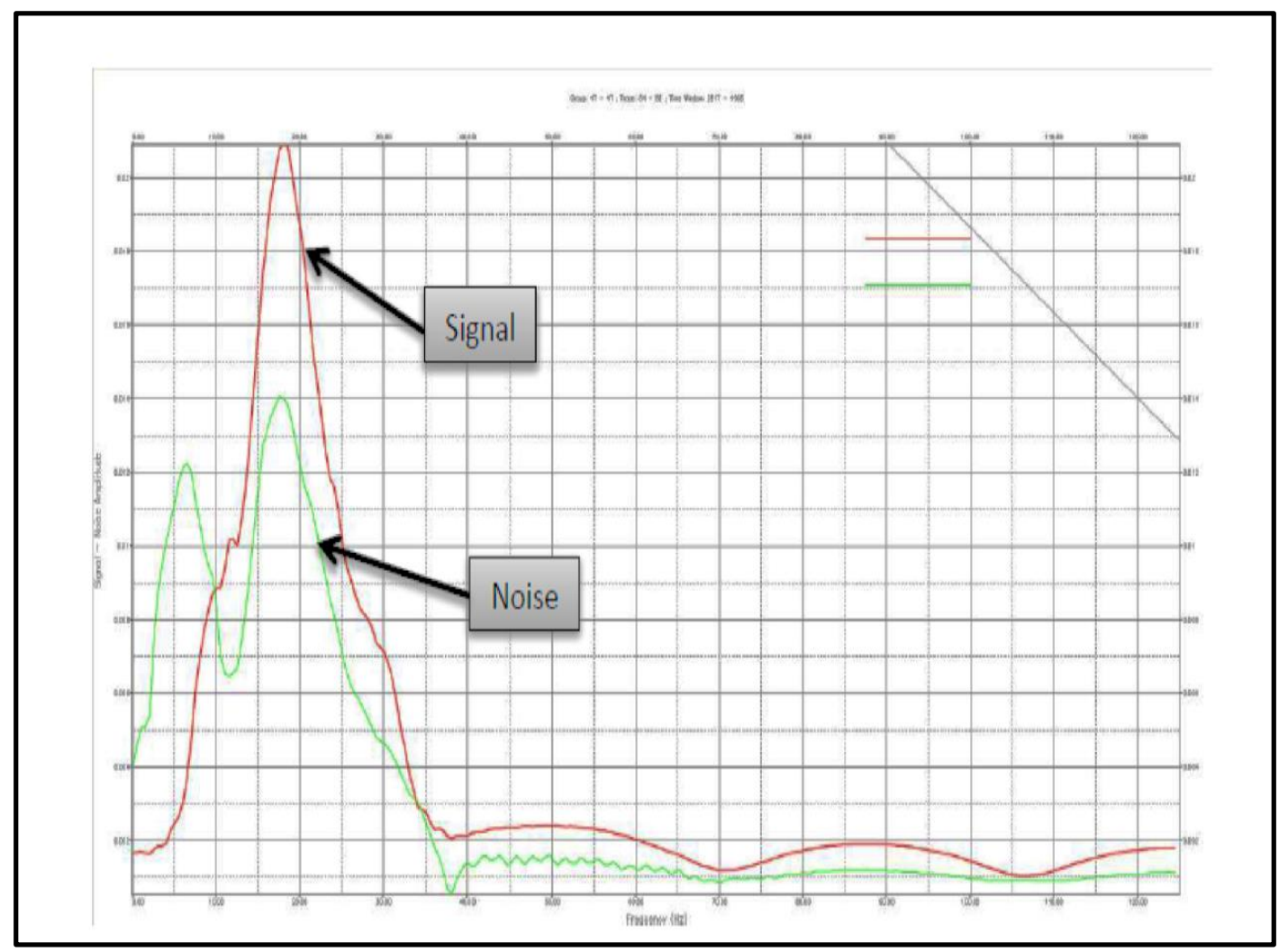

Figure 5- Spectrum analysis after applied the FDNAT in the seismic line DE21.

\section{Conclusions}

FDNAT Filter using Geovation system is proposed to denoising random seismic noise from the $2 \mathrm{~d}$ seismic data in east Diwaniya governorate, southeastern Iraq. The proposed filter calculates the amplitude energy index in a given time window and in the same frequency window and then determines the appropriate threshold for identifying high energy amplitude. By applying the FDNAT filter on the seismic data, it gives good results for attenuating of random noise from both shots gather and stacked along the seismic line DE21. This step of processing will improve the signal and give an indication on the effectiveness of FDNAT filter for reducing random noise. Spectrum analysis of the seismic data gives evidence that FDNAT filter is a good method of seismic processing that it leads to increase the signal to noise ratio, but not to remove all the noise. It is necessary here to refer that determining the appropriate threshold for identifying high energy amplitude is subjected to the test over and over.

\section{References}

1. Yilmaz, O. 2001. Seismic Data Analysis, Processing, Inversion and Interpretation of Seismic Data, SEG, V. 1, Tulsa, Oklahoma, 836p.

2. Gan, S., Chen, X., Zu, S., Qu, S. and Zhong, W. 2015. Structure - oriented singular value decomposition for signal enhancement of seismic data. Journal of Geophysics and Engineering, 12: 262-272.

3. Chen, Y., Xue, Y., Cheng, Z., Gan, S. and Zhang, D. 2016. Random noise attenuation based on orthogonal polynomial transform in the flattened domain, 78th EAGE Conference \& Exhibition 2016 Vienna, Austria, 30 May- 2 June 2016.

4. Bacheri, M. and Riahi, M., A. 2016. Seismic data random noise attenuation using DBM filtering, Bollettineo de Geofisica Teorica de Applicata, 57(1): 1-11.

5. Canales L., L. 1984. Random noise reduction. In: 54th Annual International Meeting, SEG, Expanded Abstracts, pp. 525-527.

6. Spitz, S. and Deschizeaux, B. 1994. Random noise attenuation in data volumes FXY predictive filtering versus a signal subspace technique. In: 56th Annual Conference and Exhibition, EAGE, Extended Abstracts, H033. 
7. Lu, W., K. 2006. Adaptive noise attenuation of seismic images based on singular value decomposition and texture direction detection. J. Geophys. Eng., 3: 28-34.

8. Bekara, M. and Baan, M., V. 2007. Local singular value decomposition for signal enhancement of seismic data. Geophys., 72: 59-65.

9. Donoho, D., L., Johnstone, I., M., Kerkyacharian, G. and Picard, D. 1996. Density estimation by wavelet thresholding, Ann. Statist., 24: 508-539.

10. Starck, J., L., Candès, E., J. and Donoho, D., L. 2002. The Curvelet transform for image denoising. IEEE Trans. Image Process. 11: 670-684.

11. Teknik, F. 2015. Anomalous amplitude attenuation method to enhance seismic resolution, Journal of Aceh physics Society, 4(1): 1-3.

12. Xuan-Lin, K., Hui, C., Jin-Long, W., Zhi-Quan, H., Dan, X. and Lu-Ming, L. 2017. An amplitude suppression method based on the decibel criterion, Applied Geophysics, 14(3): 387- 398.

13. Khalid, H. 2004. Study of re-interpretation of seismic information the eastern Diwaniya area, Oil Exploration Company, internal report. (In Arabic)

14. Surface Geology Survey of Iraq General Company for Geological Survey and Mining, 2000.

15. Kazemi, K. 2009. Seismic Imaging of Thrust Fault Structures in Zagros Iranian Oil Feld, From Surface and Well Data, Ph.D. Thesis of Master of Science Geophysics (Un published), Department of Geophysics, Cergy Pontoise University, 356p .

16. Geovation User's manual, 2011. CGG Varitas Company, France.

17. Linville, A. F. and Meek, R. A. 1995. A procedure for optimally removing localized coherent noise: Geophysics, 60(1): 191-203.

18. Wang, S. Q., Meng, X. H. and Yu, C. L. 2006. Seismic abnormal amplitude self-adapting inhibition, Petroleum Geology \& Oilfield Development in Daqing, 25(5): 112- 115.

19. Wang, J., Zhou, X. Y. and Yun, C. H. 2011. Realization of surface consistent constrained anomaly amplitude attenuation technology, Geophysical Prospecting for Petroleum, 50(5): 493-498. 